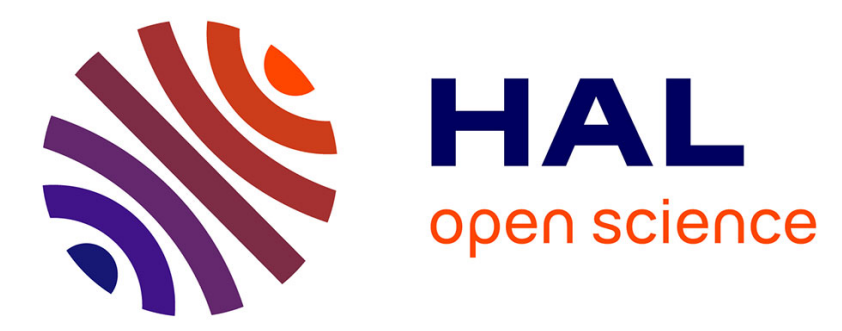

\title{
Prioritizing Digital Identity Goals - The Case Study of Aadhaar in India
}

\author{
Umar Bashir Mir, Arpan K. Kar, M. P. Gupta, R. S. Sharma
}

\section{To cite this version:}

Umar Bashir Mir, Arpan K. Kar, M. P. Gupta, R. S. Sharma. Prioritizing Digital Identity Goals The Case Study of Aadhaar in India. 18th Conference on e-Business, e-Services and e-Society (I3E), Sep 2019, Trondheim, Norway. pp.489-501, 10.1007/978-3-030-29374-1_40 . hal-02510108

\section{HAL Id: hal-02510108 https://hal.inria.fr/hal-02510108}

Submitted on 17 Mar 2020

HAL is a multi-disciplinary open access archive for the deposit and dissemination of scientific research documents, whether they are published or not. The documents may come from teaching and research institutions in France or abroad, or from public or private research centers.
L'archive ouverte pluridisciplinaire HAL, est destinée au dépôt et à la diffusion de documents scientifiques de niveau recherche, publiés ou non, émanant des établissements d'enseignement et de recherche français ou étrangers, des laboratoires publics ou privés.

\section{(c)(1)}

Distributed under a Creative Commons Attribution| 4.0 International License 


\title{
Prioritizing Digital Identity Goals - The case study of Aadhaar in India
}

\author{
Umar Bashir Mir ${ }^{1}$, Arpan K.Kar, M.P.Gupta, RS Sharma \\ Indian Institute of Technology Delhi, New Delhi 110016, India \\ ${ }^{1}$ mirumar.itdegmail.com
}

\begin{abstract}
Identity is one of the basic building blocks of the Fourth Industrial Revolution, and as the capability of digital technologies improves drastically in the last decade, identity in digital form has become unavoidable. Identity entitles an individual to various services like voting, education, employment, insurance, healthcare etc. Yet there are around 1 billion people in the world at present that do not possess any form of official identity. Lack of identity has a significant impact on people living in rural areas, especially women, children, and financially backward families. In recently released Sustainable Development Goal-16 by the UN, it has been recommended that by 2030, every individual should be given a legal identity. India's digital identity program -Aadhaar is one significant contribution in this direction considering its coverage. Rolling out a national identity scheme needs a considerable budget, time and most importantly, domain knowledge for smooth implementation. This paper attempts to identify the overarching goals of Aadhaar. The study also ranks goals based on their significance. The research uses focus group for data collection along with secondary data. The research in total identified nine primary goals with uniqueness, privacy and security as the high priority goals and scalability and future-proofing of technology as low priority goals. Total Interpretive Structural Modeling (TISM) has been used to identify the significance of each goal. This study could be taken as a starting point by other nations that are desirous of having a similar biometric identity program for its citizens.
\end{abstract}

Keywords: Aadhaar, Biometrics, CSF, Digital Identity, E-governance, MCDM, TISM, India.

\section{Introduction}

Identity of a person or a group is the mixture of their characteristics, emotions, behavior, beliefs and personality and in online space is called digital identity (DI). DI is an old concept and existed since the early days of Internet. It is a multidimensional concept and philosophically 'identity' explains 'who am I?'. It is formed of attributes that make an individual unique and distinguishable from the rest of the population [1]. The World Economic Forum (WEF) defines DI as "collection of individual attributes that describe an entity and determine the transactions in which that entity can participate" [2]. 
In the past, researchers have explored use of information technology for effective e-governance initiatives[3], governance of Internet of Things [4] and performance assessment e-government projects [3], [5], [6]. Disruptive technologies have significantly shifted transactions from offline to online mode giving rise to an era where performing transactions anonymously has become almost impossible [7]. Performing transactions over digital networks demands a secure and fool-proof mechanism for creating, exchanging and storing identities of an entity online [7]. Traditional identity documents are not compatible with today's digital needs there is a need to have trusted and secure digital identities that would facilitate faceless transaction online[8][9]. Digital identities can have positive socio-political and economic impact for a country especially emerging ones if designed and implemented properly across different application areas [10].

The continuous evolution of the digital economy worldwide mandates individuals to be uniquely identifiable to be part of the growing digital economy. In this direction, the United Nations set a target of providing "legal identity" to each by 2030 (SDG16). Perceiving the transformational capability of new age ID systems for the distribution of essential services to the people, World Bank launched ID4D project with the aim of "providing an identity and delivering digital ID-enabled services to all."

Considering the fact that at present $24 \%$ of the developing countries do not possess any kind of DI system and only $3 \%$ have a basic identity scheme which could be used in both online and offline sphere, this study is need of the hour [11]. Countries that do not have any national level identity program will need guidelines to follow such that, "identity for all" objective is achieved. Aadhaar is the shining example to follow at present for benchmarking the objectives of DI scheme. This study attempts to decode success of Aadhaar system and tries to answer following research questions:

- What are the critical success factors (CSFs) of Aadhaar?

- How to prioritize CSFs of Aadhaar based on their significance?

This paper aims to identify CSFs of Aadhaar and rank each factor based on their significance, TISM methodology has been adopted for evaluating expert's opinions.

The subsequent sections of this paper are organized as follows: Section 2 highlights the need of digital identity systems and presents Aadhaar as a case study for this research. Section 3 presents the theoretical aspects of this study. Section 4 focuses on the research questions and gaps identified in the domain. Section 5 introduces focus group members and TISM methodology for ranking CSFs identified in section 3. Finally, implications of this research are discussed followed by the conclusion.

\section{$2 \quad$ Literature Review}

With population more than 1.3 billion, India is the second most populous country in the world and it became the first country to roll out digital identity scheme on such a large scale for its citizens [11]. DI and its management have been in focus among the research community in recent past, most of the research on DI systems have focused on the implication side of it [12]-[14]. 
Extensive literature in the form of reports and studies is available which highlights that management of DI is still in its infancy stage, full potential of the digital economy could be accomplished only after having a sophisticated system in place for the issuance, storing and management of digital identities [15]. It's because the online communications possess a significant level of risk, and security measures to deal with these risks in present DI management systems is not enough. This asymmetry results in a lack of confidence in the digital transaction [16]. Many governments across the world are taking initiatives to address this asymmetry and have initiated programs at national level to provide digital identities to its citizens that are verifiable and secure [17]. Examples of some of the countries that have a digital identity system in place are Canada, UK, Sweden, Estonia, Nigeria, and Argentina.

Nations around the world want to develop a connected and interoperable global digital economy with digital identities at the core [18]. Because of the high variance among national DI systems in terms of their scope and functionality, developing an effective and efficient DI system is subject to multiple risks in terms of time, budget, adoption, implementation, security and utility [19] .

With the improvements in biometric precision, biometrics is becoming the vital part of an identity systems, traits like retina, face, voice and iris could be used for identification purpose [20]. Any trait could be used for identification purpose if it is universal, unique, permanent, and recordable. Because of its unique features, it has found application in various areas like security [21], healthcare and attendance [22] , surveillance [21], and law [23].

\subsection{Aadhaar -A case study from India}

Aadhaar is an initiative by the Government of India that is meant to provide every resident of India a unique identity number. It addresses 'identity gap' of India [24]. This unique identity number is tightly coupled with individual's biometrics like their photograph, fingerprint's of both hands and iris scan [25]. This Aadhaar number is used by both private and public sector platforms as proof of address where ever required. Supreme Court in 2013 ruled out that Aadhaar is not mandatory for enrolling in any government programs. However, Aadhaar Bill was passed by the Lok Sabha in 2016 which allows use of Aadhaar for delivery of various subsidies through Direct Benefit Transfer (DBT), and other benefits and services [26]. Aadhaar has made the existing welfare schemes more effective and efficient by targeting beneficiaries directly. The Aadhaar platform is indicative of the changing forms of a state and citizen relation in which the citizens are regularly redefined as customers of government for services [27]. Main purpose of Aadhaar is to provide unique identification and authentication service and is achieved with the help of biometrics [24]. Aadhaar is a twelve digit random number linked with the biometrics of a resident e.g. photo, fingerprints of hands, iris scan and demographic details e.g. date of birth, gender etc. [32]. India has issued Aadhaar cards to more than 1 billion residents [14].

Inclusion of biometrics in Aadhaar has helped to deal with the gaps in the existing systems -to ensure legal identity and to extend social protection schemes. Aadhaar is aligned with the main elements of SDGs-16 [17] i.e. right to identity and development of a sound system to guarantee social protection by preventing leakages and misman- 
agement in various welfare schemes, absence of identification documents, scalability, lack of trusted platform for financial transactions and the presence of large number of fake beneficiaries [30].

\section{Theoretical Lens}

This study attempts to identify the overarching latent goals of India's digital identity system -Aadhaar, under the backdrop of extensively used theory called Critical Success Factors Theory.

\subsection{Critical success factors theory}

The concept of "Critical Success Factors" was first introduced by Rockart in 1979 [31]. Initially used mostly in the context of project management and gradually it has found its application in other different domains like smart cities [32], supply chain [33], business intelligence [34]. CSFs define fundamental zones of action in which positive outcomes are essential for a specific organization to achieve its primary goal, these are the conditions, qualities or factors that must go right for the success of an organization.

We did comprehensive literature review of various secondary data; research papers related to digital identity, Aadhaar, Estonia digital identity, e-governance, and SSN from Scopus database were taken into consideration for this study. Apart from research articles, we also considered official reports from government especially UIDAI and news articles published by some of the leading online news portals. A total of forty key factors were identified that are refined regrouped and classified into fifteen generic themes out of which nine were selected as CSFs (also known as overarching goals) by experts. This addresses our first research question, to identify CSFs of Aadhaar. These nine CSFs are shown in Table 1 and are used for further analysis.

Table 1: CSFs of Aadhaar

\begin{tabular}{|r|l|}
\hline S1. No. & Factors \\
\hline 1. & Building it as a Platform \\
\hline 2. & Future-proofing of Technology \\
\hline 3. & Data Security \& Privacy \\
\hline 4. & Scalability \\
\hline 5. & Inclusion \\
\hline 6. & Uniqueness of IDS \\
\hline 7. & Cost Optimization \\
\hline 8. & Speed \\
\hline 9. & Resident Convenience \\
\hline
\end{tabular}

\section{$4 \quad$ Research Questions}

To the best of our knowledge, there is no such study found in the existing research which has attempted to identify and rank the CSFs of any digital identity system like 
Aadhaar. Majority of the research on biometric identities explores its utilitarian aspects and privacy and security concerns [38]. Hence, the motivation for this research is to analyze India's digital identity program -Aadhaar. The flow of this research is shown in the fig 1 .

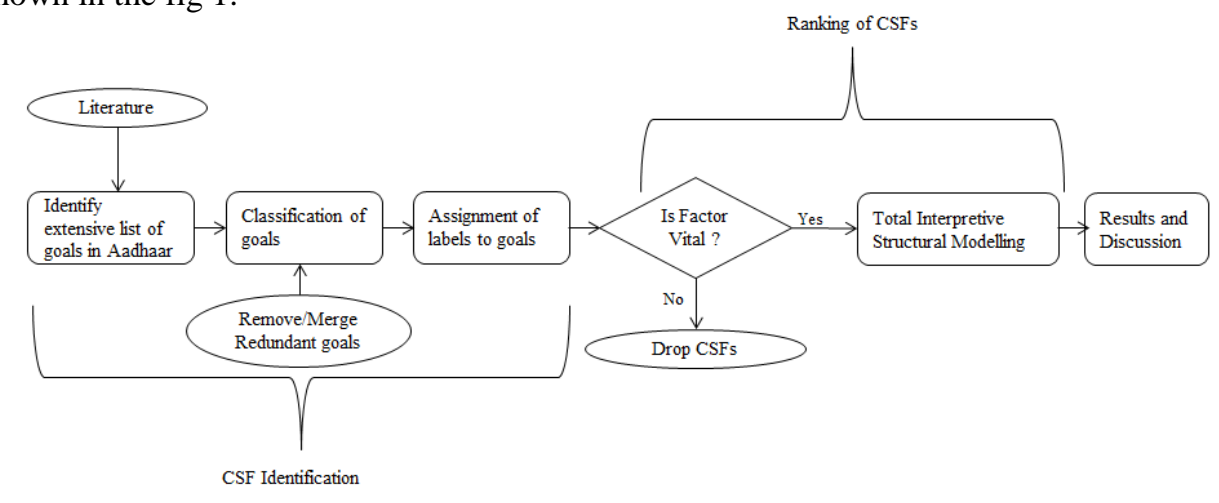

Fig 1: Research flow diagram

\section{$5 \quad$ Research Methodology}

This study used focus group methodology to identify the significance level of each goal, it is a well-established systematic technique for synthesizing the opinions of domain specific experts on specific issues. This method is extremely useful in investigating different beliefs and thoughts on a particular issue in detail in presence of a moderator who oversees and records the deliberations. [36].

In this study, focus group of eight-members was formed. Each member had direct association with Aadhaar and had experience of more than fifteen years; they were selected and approached using personal connections. Details of the focus group participants are shown in Table 2:

\begin{tabular}{|l|l|}
\multicolumn{2}{|c|}{ Table 2: Focus groups details } \\
\begin{tabular}{|l|l|}
\hline No. of participants & 8 \\
\hline Duration of interview (minutes) & 45 (approx.) \\
\hline Male: Female & $6: 2$ \\
\hline Indian Administrative Service Officer (IAS) & 3 \\
\hline Management Professional & 2 \\
\hline Dy. Director General (DDG) & 1 \\
\hline Secretary & 1 \\
\hline Senior Govt. Official & 1 \\
\hline Minimum experience (years) & 15 \\
\hline
\end{tabular}
\end{tabular}

\subsection{Focus group protocol}

Focus group discussion started with a short welcome note, and all members were appreciated for their participation in the discussion. One of the authors moderated the session and was accompanied by an assistant responsible for taking notes, and before the discussion was started, every member of the group was requested to submit a con- 
sent form. The consent form had details like discussion being recorded in writing (taking notes) and digitally (audio), and all transcripts to be kept anonymous. For the sake of confidentially, each participant had a nameplate in front of them showing their first name only. Lastly, the moderator emphasized the objective of the focus group, which was to identify the overarching goals (CSFs) of Aadhaar and then determining the relative significance of each goal corresponding to other goals.

\subsection{Identification of overarching goals of Aadhaar}

Identification of relevant constructs empowers the decision makers to visualize the impact of actions [37]. Goals identified from the secondary data sources were evaluated by focus group participant; based on the consensus of the participants, some identified goals were clubbed, dropped, renamed, and some new were added. This method has subdued the duplicity in goals and has improved overall knowledge of the study. The final list of overarching goals is mentioned in table 3 .

\subsection{Total Interpretive Structural Modeling - TISM}

TISM, which is the modified version of ISM - method that is used to convert unclear and ambiguous mental representations into clear visible models [38]. Both TISM and ISM has been used extensively in the literature, [39] [40] and in this study it is used to rank overarching goals of Aadhaar system.

Table 3: Coding and Labeling Scheme of Identified Goals

\begin{tabular}{|r|l|l|c|}
\hline Sl.No & \multicolumn{1}{|c|}{ Goal } & \multicolumn{1}{c|}{ Label } & Code \\
\hline 1. & Building it as a platform & Platform & F1 \\
\hline 2. & $\begin{array}{l}\text { Future-proofing } \\
\text { technology }\end{array}$ & Future-proofing & F2 \\
\hline 3. & Data Security and privacy & $\begin{array}{l}\text { Security and } \\
\text { Privacy }\end{array}$ & F3 \\
\hline 4. & Scalability & Scalability & F4 \\
\hline 5. & Inclusion & Inclusion & F5 \\
\hline 6. & Uniqueness of IDS & Uniqueness & F6 \\
\hline 7. & Cost Optimisation & Cost & F7 \\
\hline 8. & Speed & Speed & F8 \\
\hline 9. & Resident Convenience & Convenience & F9 \\
\hline
\end{tabular}

TISM generates a hierarchical model by multiple pairwise comparisons using ISM methodology introduced by Warfield in 1974 [38]. In this study, a six steps TISM method is followed and is described as follows:

1. Identification of overarching goals of Aadhaar.

2. Based on expert's inputs, determine contextual relationships among factors identified in step 1 and develop Structural Self-Interaction Matrix (SSIM).

3. Develop Reachability Matrix (RM) from SSIM and check for transitive relations.

4. Do level partitioning on RM

5. Develop canonical matrix based on the final stage of partitioning matrix. 
6. Finally, convert canonical matrix into hierarchical diagraph in which factors (i.e. Goals) are represented by nodes and edges represent relationship (i.e. significance of goals) among nodes.

To determine contextual relation between factors, the following four symbols are used and have following interpretation: $V$ : if $i$ helps in $j$ and $j$ does not help in $i$; A: if $i$ does not help in $\mathrm{j}$ but $\mathrm{j}$ helps in $\mathrm{i}$; $\mathrm{X}$ : if both $\mathrm{i}$ and $\mathrm{j}$ help each other and $\mathrm{O}$ : if $\mathrm{i}$ and $\mathrm{j}$ do not help each other.

Table 4: Structured Self-interaction Matrix

\begin{tabular}{|lllllllll|}
\hline & F9 & F8 & F7 & F6 & F5 & F4 & F3 & F2 \\
F1 & A & A & A & A & A & V & A & V \\
F2 & A & A & A & A & A & X & A & \\
F3 & V & V & V & A & V & V & & \\
F4 & A & A & A & A & A & & & \\
F5 & A & A & A & A & & & & \\
F6 & V & V & V & & & & & \\
F7 & X & X & & & & & & \\
F8 & X & & & & & & & \\
\hline
\end{tabular}

Step by step implementation of TISM methodology adopted for prioritization is explained below:

Step 1: A total of forty key factors were identified that are refined regrouped and classified into fifteen generic themes out of which nine were selected for this study (see Table 3).

Step 2: A focus group of eight members were employed to analyses the significance of nine CSFs and their relationships with each other. The association between factors is evaluated using "yes" or "no" queries. The final Self-interaction matrix is shown in see Table 4.

Step 3: All the identified relations are represented in the binary matrix called reachability matrix (see Table 5). Each entry in the matrix represents a relationship between two goals.

Step 4: All entries in the RM are checked for additional transitive relations that are not covered already. In our case, no additional transitive relations were discovered.

Table 5: Reachability Matrix (binary)

\begin{tabular}{|llllllllll|}
\hline & F1 & F2 & F3 & F4 & F5 & F6 & F7 & F8 & F9 \\
F1 & 1 & 1 & 0 & 1 & 0 & 0 & 0 & 0 & 0 \\
F2 & 0 & 1 & 0 & 1 & 0 & 0 & 0 & 0 & 0 \\
F3 & 1 & 1 & 1 & 1 & 1 & 0 & 1 & 1 & 1 \\
F4 & 0 & 1 & 0 & 1 & 0 & 0 & 0 & 0 & 0 \\
F5 & 1 & 1 & 0 & 1 & 1 & 0 & 0 & 0 & 0 \\
F6 & 1 & 1 & 1 & 1 & 1 & 1 & 1 & 1 & 1 \\
F7 & 1 & 1 & 0 & 1 & 1 & 0 & 1 & 1 & 1 \\
F8 & 1 & 1 & 0 & 1 & 1 & 0 & 1 & 1 & 1 \\
F9 & 1 & 1 & 0 & 1 & 1 & 0 & 1 & 1 & 1 \\
\hline
\end{tabular}

Step 5: For each goal from the reachability matrix, three sets are obtained, i.e. reachability set, antecedent set, and intersection set of reachability and antecedent set that form partitioning matrix (see Table 6). A particular goal is assigned a level if the intersection set is same as the reachability set for that particular goal. Once a goal is assigned a level, it is removed from the subsequent iterations. This process is repeated 
until each goal is assigned a level. In this study, a total of six iterations were performed.

Step 6: Finally, the partitioning matrix is converted into TISM hierarchy model as shown in fig 2. This model is drawn from bottom to top where bottom level goals are most significant and top level goals are less significant. Uniqueness (level 6) is at the bottom of TISM hierarchical model which signifies it is the most significant goal whereas future-proofing and scalability (level 1) are at the top level and are considered as less significant.

Partitioning is applied multiple times till level of each factor is identified; it took six iterations to identify level of each factor in Table 6 .

Table 6: Final Partitioning Matrix

\begin{tabular}{|c|c|c|c|c|}
\hline Element & Reachability & Antecedents & Intersection & Levels \\
\hline F1 & $\{\mathrm{F} 1, \mathrm{~F} 2, \mathrm{~F} 4\}$ & $\{\mathrm{F} 1, \mathrm{~F} 3, \mathrm{~F} 5, \mathrm{~F} 6, \mathrm{~F} 7, \mathrm{~F} 8, \mathrm{~F} 9\}$ & $\{F 1\}$ & II \\
\hline F2 & $\{\mathrm{F} 2, \mathrm{~F} 4\}$ & $\begin{array}{l}\{\mathrm{F} 1, \mathrm{~F} 2, \mathrm{~F} 3, \mathrm{~F} 4, \mathrm{~F} 5, \mathrm{~F} 6, \mathrm{~F} 7, \mathrm{~F} \\
8, \mathrm{~F} 9\}\end{array}$ & $\{\mathrm{F} 2, \mathrm{~F} 4\}$ & I \\
\hline F3 & $\begin{array}{l}\{\mathrm{F} 1, \mathrm{~F} 2, \mathrm{~F} 3, \mathrm{~F} 4, \mathrm{~F} 5, \mathrm{~F} 7, \\
\mathrm{F} 8, \mathrm{~F} 9\}\end{array}$ & $\{\mathrm{F} 3, \mathrm{~F} 6\}$ & $\{F 3\}$ & V \\
\hline F4 & $\{\mathrm{F} 2, \mathrm{~F} 4\}$ & $\begin{array}{l}\{\mathrm{F} 1, \mathrm{~F} 2, \mathrm{~F} 3, \mathrm{~F} 4, \mathrm{~F} 5, \mathrm{~F} 6, \mathrm{~F} 7, \mathrm{~F} \\
8, \mathrm{~F} 9\}\end{array}$ & $\{\mathrm{F} 2, \mathrm{~F} 4\}$ & I \\
\hline F5 & $\{\mathrm{F} 1, \mathrm{~F} 2, \mathrm{~F} 4, \mathrm{~F} 5\}$ & $\{\mathrm{F} 3, \mathrm{~F} 5, \mathrm{~F} 6, \mathrm{~F} 7, \mathrm{~F} 8, \mathrm{F9}\}$ & $\{$ F5 $\}$ & III \\
\hline F6 & $\begin{array}{l}\{\mathrm{F} 1, \mathrm{~F} 2, \mathrm{~F} 3, \mathrm{~F} 4, \mathrm{~F} 5, \mathrm{~F} 6, \\
\mathrm{F} 7, \mathrm{~F} 8, \mathrm{~F} 9\}\end{array}$ & $\{\mathrm{F} 6\}$ & $\{$ F6 $\}$ & VI \\
\hline F7 & $\begin{array}{l}\{\mathrm{F} 1, \mathrm{~F} 2, \mathrm{~F} 4, \mathrm{~F} 5, \mathrm{~F} 7, \mathrm{~F} 8, \\
\mathrm{F} 9\}\end{array}$ & $\{\mathrm{F} 3, \mathrm{~F} 6, \mathrm{~F} 7, \mathrm{~F} 8, \mathrm{~F} 9\}$ & $\{\mathrm{F} 7, \mathrm{~F} 8, \mathrm{~F} 9\}$ & IV \\
\hline F8 & $\begin{array}{l}\{\mathrm{F} 1, \mathrm{~F} 2, \mathrm{~F} 4, \mathrm{~F} 5, \mathrm{~F} 7, \mathrm{~F} 8, \\
\text { F9 }\}\end{array}$ & $\{\mathrm{F} 3, \mathrm{~F} 6, \mathrm{~F} 7, \mathrm{~F} 8, \mathrm{~F} 9\}$ & $\{\mathrm{F} 7, \mathrm{~F} 8, \mathrm{~F} 9\}$ & IV \\
\hline F9 & $\begin{array}{l}\{\mathrm{F} 1, \mathrm{~F} 2, \mathrm{~F} 4, \mathrm{~F} 5, \mathrm{~F} 7, \mathrm{~F} 8, \\
\text { F9\} }\end{array}$ & $\{\mathrm{F} 3, \mathrm{~F} 6, \mathrm{~F} 7, \mathrm{~F} 8, \mathrm{F9}\}$ & $\{\mathrm{F} 7, \mathrm{~F} 8, \mathrm{F9}\}$ & IV \\
\hline
\end{tabular}

In the final step, partitioning matrix is transformed into TISM hierarchical model (see fig 2). The result of this TISM model will enable concerned authorities to focus on the most important elements first while developing a digital identity solution.

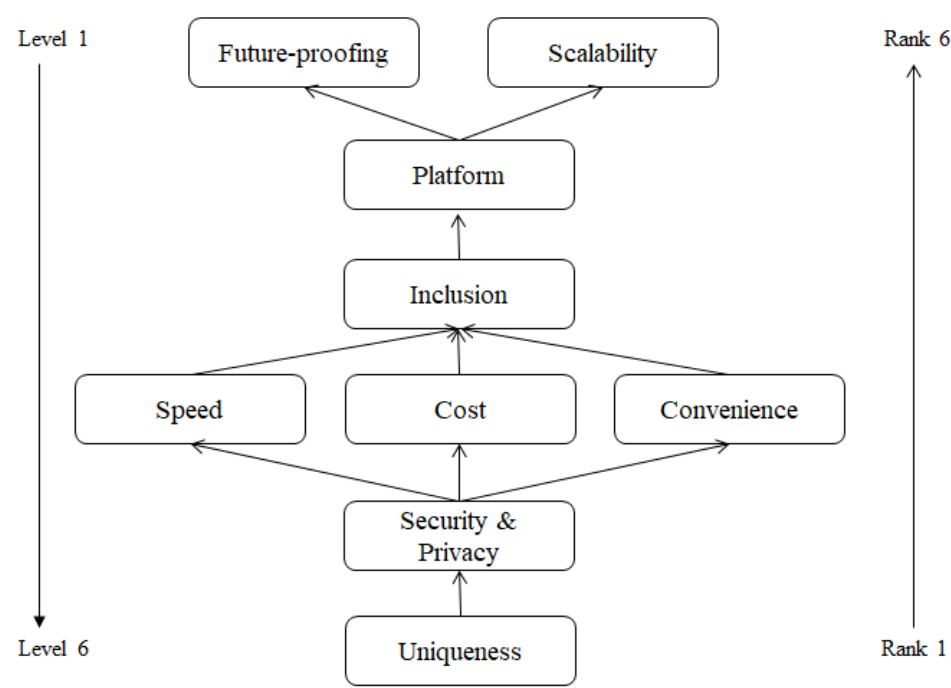

Fig 2: Prioritization of CSFs of Aadhaar 


\section{Discussion}

This section highlights the insights derived from this research. It can be observed that developing a biometric enabled digital identity system is a complex task and we need to take all stakeholders into consideration for successful development and implementation of the project. Most existing identity systems in place are functional identity systems - primarily developed for a particular use case like voter ID. Some of the high risks associated in developing a country level digital identity system are accurate budget calculation, securing assets, manpower with desirable skills, and availability of required technology, policy documentation, and maintenance of the overall system. To avoid risks which could cause project failure an extensive action plan is must to have. To the best of our knowledge, we have not found any research in existing academic research literature related to the ranking and identifying significance of goals of Aadhaar.

The findings depict that uniqueness with level six is the most significant goal followed by security and privacy that is at level five. This could easily be explained as these three are the fundamentals of any identity system and the same was reciprocated by the experts. Any identity system would lose its utility and robustness if any of these are compromised. Speed, cost and convenience share level four and equal significance; these are factors which would define the efficiency aspect of the Identity system and the performance of the system would be measured in their terms. Inclusion at level three is followed by platform that is at level two which signifies inclusion is slightly more significant as compared to platform, scalability and future-proofing of technology; this is because of the fact that India is a country of diversities and exclusion has been a long-standing foe for Government plans focusing on growth. So, inclusion received a special focus and was closely associated with the performance based factors that featured on the previous level; it plays a critical role of making Aadhaar into a successful platform which is on the next level and encompasses factors like infrastructural requirements and service delivery supply-chain. Scalability and future-proofing of the technology are both at level one and they focus on the future of this platform keeping in view the rapid growth of population and the changing nature of utilities or services expected out of the platform.

\subsection{Implications of the study}

It is always a good practice to take successful system as a reference when developing similar one for different audience. It has been estimated that the total cost of a typical digital identity system is in-between $£ 100-250$ million [41]. Hence, it is important to analyze each risk beforehand and have measures to avoid or mitigate these types of risks. Further, digital identity could save $£ 5-10$ billion by avoiding identity related frauds [41].

The results of this study support the concept of stakeholder engagement in public schemes and for focusing at the CSFs analyzed during the overall development process. They are also consistent with the previous research that highlighted that confidentiality must be enforced over enrolment [42], [43]; also security and privacy are the second most important goal in the hierarchy. 
Regarding the methodological contribution, this study is the first of its kind to employee TISM for ranking a gigantic project in Indian context - Aadhaar and the experience gained through the methods and techniques implemented may be helpful in other studies on analyzing large scale government initiatives.

The practical implications of this study relate to the concept of using hierarchical ranking model in devising a real life digital identity project. The listed CSFs (see table 1) can help concerned authorities like governments to make policies which have the possibility of creating significant impact on the target. It shows the significance of each CSFs which will be valuable information while making feasibility analysis in terms of time required to develop an identity system, budget required, technological requirements, skill set of manpower, longevity of project, robustness of identity system and overall management of the project.

\section{Conclusion}

In this research, we identified the factors that are critical for a digital identification system. India's digital identity program - Aadhaar has been studied as a case study in this paper using CSFs theory as baseline. A total of nine CSFs are identified with the help of expert's opinion and ranked using TISM methodology which resulted in the hierarchical model as shown in Fig 2.

The findings depict that uniqueness with level six is the most significant goal followed by security and privacy that is at level five. Scalability and future-proofing of the technology are the least significant goals both at level one. Speed, cost and convenience share level four and equal significance. Inclusion at level three is followed by platform that is at level two which signifies inclusion is slightly more significant as compared to platform, scalability and future-proofing of technology.

The results of this study will act as a reference for the countries that are yet to develop a digital identity program for its inhabitants. We hope this research will motivate researchers across the globe to conduct similar research on other digital identity program and develop a ranking hierarchy which is valid universally. Directions for future research are to validate the results of this study on some more identification programs and use the ranking model in designing practical digital identity systems.

\section{References}

[1] E. T. Olson, "Personal Identity," Stanford Encyclopedia of Philosophy, 2015. [Online]. Available: https://plato.stanford.edu/entries/identity-personal/. [Accessed: 21-Apr-2019].

[2] R. J. Mcwaters, "A Blueprint for Digital Identity The Role of Financial Institutions in Building Digital Identity," World Econ. Forum, Futur. Financ. Serv. Ser., no. August, pp. 1-108, 2016.

[3] H Singh, AK kar, P Vigneswara Ilavarsana, "Assessment of e-governance projects: an integrated framework and its validation," in Proceedings of the Special Collection on eGovernment Innovations in India, 2017, pp. 124-133.

[4] S. Chatterjee and A. kumar Kar, "Regulation and governance of the Internet 
of Things in India,” Digit. Policy, Regul. Gov., vol. 20, no. 5, pp. 399-412, 2018.

[5] H. Singh, A. K. Kar, and P. V. Ilavarsana, "Performance assessment of egovernment projects: a multi-construct, multi-stakeholder perspective," in Proceedings of the 10th International Conference on Theory and Practice of Electronic Governance, 2017, pp. 558-559.

[6] A. Mishra, D. P. Misra, A. K. Kar, S. Babbar, and S. Biswas, "Assessment of Open Government Data Initiative-A Perception Driven Approach," in Conference on e-Business, e-Services and e-Society, 2017, pp. 159-171.

[7] Jeremy Rifkin, "The Age of Access: The New Culture of Hypercapitalism Where All of Life Is a Paid-For Experience," Putnam Publishing Group, 2001.

[8] N. k. Baym, Personal connections in the digital age, 2nd ed. Malden, USA: Polity Press, 2015.

[9] A. M. Al-Khouri, "Digital identity: Transforming GCC economies," Innov. Manag. Policy Pract., vol. 16, no. 2, pp. 184-194, 2014.

[10] McKinsey, "Digital Identification : A Key To Inclusive Growth," 2019.

[11] BankWorld, World Development Report 2016: Digital Dividends. The World Bank, 2016.

[12] T. N. Herbert Kubicek, "Different countries-different paths extended comparison of the introduction of eIDs in eight European countries," Identity Inf. Soc., vol. 3, no. 1, pp. 235-245, 2010.

[13] S. Agrawal, S. Banerjee, and S. Sharma, "Privacy and Security of Aadhaar: A Computer Science Perspective,” vol. 52, no. 37, pp. 1-23, 2017.

[14] P. Dixon, "A Failure to B Do No Harm ${ }^{\wedge}$ - India' s Aadhaar biometric ID program and its inability to protect privacy in relation to measures in Europe and the U. S .," 2017.

[15] OCED, "Digital identity management: enabling innovation and trust in the internet economy.," Te Organisation for Economic Co-operation and Development (OECD), 2011. .

[16] R. F. Elisa Bertino, Federica Paci, "Privacy-preserving Digital Identity Management for CloudComputing," IEEE Comput. Soc. Tech. Comm. Data Eng., 2009.

[17] UN, "SDG," UNDP, 2016. [Online]. Available: https://www.un.org/sustainabledevelopment/peace-justice/. [Accessed: 08Feb-2019].

[18] J. Atick, "Digital identity: the essential guide," ID4Africa Identity Forum, $2016 . \quad$ [Online]. Available: http://www.id4africa.com/prev/\%0Aimg/Digital_Identity_The_Essential_Gui de.pdf.

[19] F. B. Leo F. Goodstadt, Regina Connolly, "The Hong Kong e-Identity Card: Examining the Reasons for Its Success When Other Cards Continue to Struggle," Inf. Syst. Manag., vol. 32, no. 1, pp. 72-80, 2015.

[20] T. N. Science and T. Matsumoto, "Biometrics Biometrics," pp. 3-5, 2012.

[21] U. Hodeghatta and R. Nayak, "Physical Security and Biometrics," in The InfoSec Handbook, SpringerLink, 2014, pp. 293-306. 
[22] D. Marohn, "Biometrics in healthcare," Biometric Technol. Today, vol. 14, no. 9, pp. 9-11, 2006.

[23] A. K. Jain, A. Ross, and S. Prabhakar, "An introduction to biometric recognition,” IEEE Trans. Circuits Syst. Video Technol., vol. 14, no. 1, pp. 420, 2004.

[24] A. Gelb and J. Clark, "Performance Lessons from India 's Universal Identification Program CGD Policy Paper 020 May 2013,” no. May, 2013.

[25] J. T. Weinberg, "Biometric identity," Commun. ACM, vol. 59, no. 1, pp. 3032, Dec. 2016.

[26] T. E. Times, "Government Notifies Aadhaar Act," The Economic Times, 2016. [Online]. Available: https://economictimes.indiatimes.com/news/economy/policy/governmentnotifies-aadhaar-act/articleshow/51585001.cms?from=mdr. [Accessed: 06Apr-2019].

[27] Jayal and N. Gopal, “A Democratic Deficit: Citizenship and Governance in the Era of Globalisation.," Glob. Gov. Reforms Dev. India, pp. 97-112, 2007.

[28] P. Barnwal, "Curbing Leakage in Public Programs with Direct Benefit Transfers Evidence from India 's Fuel Subsidies and Black Markets," Work. Pap., no. November 2014, 2015.

[29] UIDAI, "UIDAI Strategy Overview Creating a Unique Identity Number for Every Resident in India," pp. 1-45, 2010.

[30] A. Bhatia and J. Bhabha, "India 's Aadhaar scheme and the promise of inclusive social protection," Oxford Dev. Stud., vol. 0818, no. December, pp. 1-16, 2017.

[31] Christine, V., J. Bullen, F., and Rockart, "A Primer on Critical Success Factors," Rise Manag. Comput., 1981.

[32] M. G. Sheshadri Chatterjee, Arpan Kumar Kar, "Critical success factors to establish 5G network in smart cities: Inputs for security and privacy," J. Glob. Inf. Manag., vol. 25, no. 2, pp. 15-37, 2017.

[33] R. Shankar, R. Gupta, and D. K. Pathak, "Modeling critical success factors of traceability for food logistics," Transp. Res. Part E, vol. 119, no. August 2017, pp. 205-222, 2018.

[34] A. P. Yeoh, William, "Extending the understanding of critical success factors for implementing business intelligence systems.," J. Assoc. Inf. Sci. Technol., vol. 67, no. 1, pp. 134-147, 2016.

[35] G. Fenu, M. Marras, and L. Boratto, "A multi-biometric system for continuous student authentication in e-learning platforms," Pattern Recognit. Lett., 2017.

[36] M. A. C. Richard A. Krueger, Focus Groups: A Practical Guide for Applied Research, 4th ed. Sage, 2009.

[37] R. C. D. Theunis F.P.Henning, SugandreeMuruvan, Wanhua A.Feng, "The development of a benchmarking tool for monitoring progress towards sustainable transportation in New Zealand," Transp. Policy, vol. 18, no. 2, pp. 480-488, 2011.

[38] Sushil, "Interpreting the interpretive structural model," Glob. J. Flex. Syst. Manag., vol. 13, no. 2, pp. 87-106, 2012. 
[39] H. Kumar, M. K. Singh, and M. P. Gupta, "A policy framework for city eligibility analysis: TISM and fuzzy MICMAC-weighted approach to select a city for smart city transformation in India," Land use policy, vol. 82, no. February 2018, pp. 375-390, 2018.

[40] R. Dubey and S. S. Ali, "Identification of flexible manufacturing system dimensions and their interrelationship using total interpretive structural modelling and fuzzy MICMAC analysis," Glob. J. Flex. Syst. Manag., vol. 15, no. 2, pp. 131-143, 2014.

[41] I. Identity, "Digital Identity in the UK : The cost of doing nothing," no. April, 2018.

[42] N. V. Mali and M. A. Avila-Maravilla, "Convergence or Conflict?," Proc. 11th Int. Conf. Theory Pract. Electron. Gov. - ICEGOV '18, pp. 443-448, 2018.

[43] D. Belanche-gracia, L. V Casaló-ariño, and A. Pérez-rueda, "Determinants of multi-service smartcard success for smart cities development: A study based on citizens ' privacy and security perceptions," Gov. Inf. Q., vol. 32, no. 2, pp. 154-163, 2015. 